\title{
Not belonging where others do: A cross-sectional analysis of multi-level social capital interactions on health and mental wellbeing in Wales
}

Saville, Christopher

\section{Journal of Epidemiology and Community Health}

\author{
DOI: \\ 10.1136/jech-2020-215188
}

Published: 01/04/2021

Peer reviewed version

Cyswllt i'r cyhoeddiad / Link to publication

Dyfyniad o'r fersiwn a gyhoeddwyd / Citation for published version (APA):

Saville, C. (2021). Not belonging where others do: A cross-sectional analysis of multi-level social capital interactions on health and mental wellbeing in Wales. Journal of Epidemiology and Community Health, 75(4), 349-356. https://doi.org/10.1136/jech-2020-215188

\footnotetext{
Hawliau Cyffredinol / General rights

Copyright and moral rights for the publications made accessible in the public portal are retained by the authors and/or other copyright owners and it is a condition of accessing publications that users recognise and abide by the legal requirements associated with these rights.

- Users may download and print one copy of any publication from the public portal for the purpose of private study or research.

- You may not further distribute the material or use it for any profit-making activity or commercial gain

- You may freely distribute the URL identifying the publication in the public portal ?
}

Take down policy

If you believe that this document breaches copyright please contact us providing details, and we will remove access to the work immediately and investigate your claim. 
Not belonging where others do: A cross-sectional analysis of multi-level social capital interactions on health and mental wellbeing in Wales

Christopher W.N. Saville

North Wales Clinical Psychology Programme, School of Psychology, Bangor University

ORCID ID: 0000-0003-4870-7630

\section{Corresponding Author:}

Chris Saville

North Wales Clinical Psychology Programme,

School of Psychology,

Brigantia Building,

Penrallt Road

Bangor University,

Bangor, Gwynedd

Wales

LL57 2AS

Email: c.saville@bangor.ac.uk

Tel: 01248388740

Declaration on competing interests: None declared

Licence for Publication:

The Corresponding Author has the right to grant on behalf of all authors and does grant on behalf of all authors, an exclusive licence (or non-exclusive for government

employees) on a worldwide basis to the BMJ Publishing Group Ltd to permit this article (if accepted) to be published in JECH and any other BMJPGL products and sublicences such use and exploit all subsidiary rights, as set out in our licence (https://authors.bmj.com/policies/\#copyright)

Acknowledgements: I am very grateful to the survey team at the Welsh Government for providing access to data, and to two anonymous reviewers for their helpful comments. This article is dedicated to the memory of my mother, Jenny Saville (1948-2020).

\section{What is already known on this subject?}

Although ecological social capital is generally thought of as a protective factor for health, evidence suggests that it may be a risk factor for people with low individuallevel social capital. However, previous studies have measured exposure to ecological social capital at relatively coarse levels of geography, such as countries or major cities.

\section{What does this study add?}

The present study examines this phenomenon to the neighbourhood level.

Living in a neighbourhood with high ecological social capital is associated with better health in those with high individual-level social capital, but poorer health in those with low individual-level social capital. 


\begin{abstract}
Background: Social capital may be a social good in health terms, but it is not necessarily a universal good. Several studies have shown that while there is a positive association between ecological social capital and health in people with high individuallevel social capital, this relationship is weaker or even reversed in those with low individual-level social capital. Such studies, however, have used relatively coarse levels of geography for quantifying ecological social capital. The present study looks at this relationship at a more fine-grained spatial scale.

Methods: Data from the National Survey for Wales $(n=27,828$, weighted mean age $=48.4)$ were linked with previously published small-area estimates $(n=410)$ of ecological social capital for Wales. Mixed effects models were then used to assess whether the relationship between mental wellbeing and self-reported health on one hand, and ecological social capital (sense of belonging) on the other, was moderated by individual-level social capital.

Results: The models found the same moderation of the relationship that has been demonstrated previously: Although ecological social capital is positively associated with health in respondents with high individual-level social capital, the relationship is negative in those with low individual-level social capital.

Conclusion: This study replicates this association at a spatial scale orders of magnitude more fine-grained than had been shown previously. Ecological social capital is not an unambiguously positive factor for public health, and may be a risk factor for marginalised people.
\end{abstract}





\section{Crynodeb}

Cefndir: Gallai cyfalaf cymdeithasol fod yn fudd cymdeithasol ond ddim o reidrwydd yn fudd cyffredinol. Mae sawl astudiaeth wedi dangos er bod perthynas bositif rhwng cyfalaf cymdeithasol ecolegol ac iechyd i bobl gyda chyfalaf cymdeithasol unigol uchel, mae'r berthynas yn wan neu hyd yn oed yn negatif i bobl gyda chyfalaf cymdeithasol unigol isel. Mae'r astudiaethau yma wedi defnyddio unedau daearyddol bras i feintioli cyfalaf cymdeithasol ecolegol.

Dulliau: Cysylltwyd data o Arolwg Cenedlaethol Cymru (n=27,828) gydag amcangyfrifon cyfalaf cymdeithasol ecolegol ardaloedd bach yng Nghymru o astudiaeth blaenorol. Defnyddwyd modelau aml-lefel i asesu os oedd y berthynas rhwng iechyd a chyfalaf cymdeithasol ecolegol (ymdeimlad o berthyn) wedi ei chymedroli gan gyfalaf cymdeithasol unigol.

Canlyniadau: Dangosodd y modelau'r un cymedroliad o berthyn a ddangoswyd o'r blaen. Er bod perthynas positif rhwng cyfalaf cymdeithasol ecolegol ac iechyd i bobl gyda chyfalaf cymdeithasol unigol uchel, roedd y berthynas yn negatif i bobl gyda chyfalaf cymdeithasol unigol isel.

Casgliadau: Dyblygodd yr astudiaeth y ffenomen ar raddfa ofodol mwy fân-ronynnog nag astudiaethau blaenorol. Nid yw cyfalaf cymdeithasol ecolegol yn ffactor positif diamwys o ran iechyd cyhoeddus, a gallai fod yn ffactor risg i bobl sydd wedi eu ymyleiddio. 
There is a widely replicated positive association between social capital, resources embedded in social networks, and health[1-3]. This association does not just apply on the individual level. Living in an area where residents have greater social capital - i.e. ecological social capital - is also associated with better health[4-6].

Social capital, however, while a social good, is not necessarily a universal good. Evidence[7] shows that strong ecological social capital can be associated with negative health outcomes for those who are not members of the relevant social networks.

This is demonstrated by an analysis[8] of the 2000 Social Capital Community Benchmark Survey in the United States, showing that area-level social trust - a facet of social capital - was positively associated with self-reported health in respondents with high individual-level social trust, but negatively associated in those with low social trust. A similar analysis[9] of World Values Survey data, found a more positive relationship between country-level social capital and self-reported health in respondents with high individual-level social capital than those with low individuallevel social capital. Analyses of the European Social Survey[10,11] found similar results, also on the country-level, while a further analysis of the American data cited above[12] found that this relationship also applied for measures of community social capital other than social trust, such as formal participation in community groups.

However, ecological social capital is difficult to measure. Generally it is measured by aggregating survey responses separately for different geographical units, but this approach can lead to problems. Firstly, surveys may not be representative at finer geographical levels, either in terms of sample size or potentially by design. Thus simply aggregating survey data at neighbourhood level can lead to unreliable estimates of local social capital[13]. The other strategy, employed in most of the studies cited above, is to use high-level geographies, such as countries, where entire survey samples are available for each unit. This avoids the problems associated with using small and unrepresentative local samples, but it is not clear that country-level estimates of social capital are good proxies for the ecological social capital experienced by any given citizen. There is striking variation in ecological social capital at the neighbourhood level[4,14-16] which country-level estimates do not capture. Even the previous studies that used sub-national geographical units[8,12], looked at social capital on the levels of counties, and in some cases entire states, rather than neighbourhoods.

Fortunately, techniques exist for robustly estimating the prevalence of social attitudes in small areas using survey data. One such option is multi-level regression with poststratification (MRP), a technique borrowed from political science[17], but similar to synthetic estimate techniques used in health geography[18,19]. MRP involves fitting a multi-level regression model to survey data, predicting the variable of interest using both demographic data and area-level predictors of the variable. The model coefficients can then be post-stratified with the relative proportion of the population in each geographical area that each demographic segment makes up, according to the census. For example, if women aged 65-75 with university-level education tended to report high social capital, then areas where they formed a large proportion of the population would have higher estimated social capital. MRP estimates of social capital have been shown to be better predictors of geographical variation in mental health than the simple aggregation by area approach that is common in the literature[13]. 
The present study tests how the association between physical and mental health on one hand, and MRP small-area estimates of social capital on the other, varies as a function of individual-level social capital, using the National Survey for Wales (NSfW). Sense of belonging is used as the measure of individual and area-level social capital[20] and measures of mental wellbeing and self-reported health are used as outcome variables.

\section{Methods}

Ethics and data access

Approval for this study was granted by the ethics committee of the School of Psychology, Bangor University. Data for the NSfW are available from the UK Data Service (https://www.ukdataservice.ac.uk/, DOIs in references). Data on respondent area of residence were obtained from Welsh Government Knowledge and Analytical Services and were shared under the terms of a Data Access Agreement. The MRP estimates of belonging can be found at https:// doi.org/10.1016/j.healthplace.2019.102187. R code for running the analysis is included in Supplementary File 1.

\section{Setting}

Wales is one of the four nations of the United Kingdom. Most of the landmass is rural, with population centres in the south and, to a lesser extent, along the north coast. Significant pockets of poverty exist in the South Wales Valleys, which deindustrialised in the late $20^{\text {th }}$ century, and on the north coast, where seaside resorts declined with the advent of cheap air travel. Wales is majority English-speaking, but a substantial minority (19\%), [21] also speak Welsh, with Welsh-speaking communities concentrated in the west. Figure 1 shows a map of the area-level sense of belonging measure used in this study. Belonging is lowest in the cities of the south, the South Wales Valleys, and the eastern portion of the north coast. 


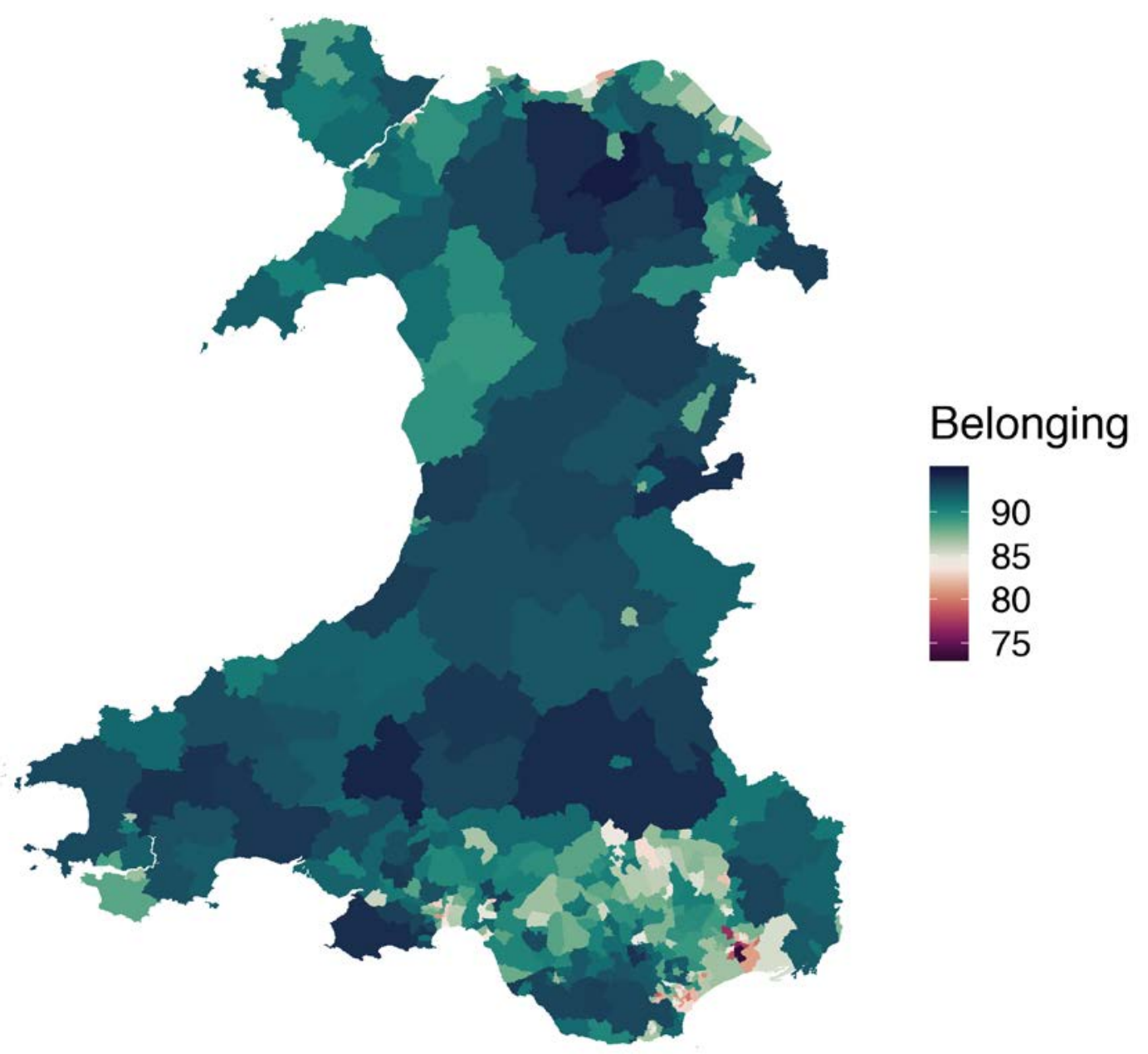

Figure 1. A map of MRP estimates of ecological sense of belonging for the 410 MSOAs in Wales.

\section{Individual-level data}

The NSfW is an annual survey of $>10,000$ Welsh residents commissioned by the Welsh Government, addressing a range of topics. The survey is designed to be representative of 16+ year olds living at private addresses in Wales. Respondents are sampled randomly from residential households identified at random from postal address files and interviewed face-to-face.

Data from the 2012-13, 2014-15, and 2018-19[22-24] waves of the NSfW were combined for the present study, as these waves included questions on wellbeing and sense of belonging. Full details of fieldwork are available from the UK Data Archive[22$24]$, but response rates were $70 \%, 64 \%$, and $54 \%$ for the $2012-13,2014-15$, and 2018 19 waves respectively. 
Data on sense of belonging, mental wellbeing, self-reported health, age, gender, education, and sampling weights were used from the three waves. Response alternatives on education changed between waves, so were recoded such that respondents had degree-level qualifications, non-degree level qualifications, or no qualifications. Age was divided into ten evenly sized segments using the cut function in $\mathrm{R}[25]$.

Sense of belonging was measured with the question "To what extent do you agree or disagree with each of the following statements: ... I belong to my local area", with the response alternatives: Strongly agree, Tend to agree, Neither agree nor disagree, Tend to disagree, and Strongly disagree. A spontaneous answer of Don't know was also permitted, but data from these participants were excluded (see below).

Wellbeing was measured using four questions, with the common stem:

"Next, I would like to ask you some questions about your feelings on aspects of your life. There are no right or wrong answers. For each of these questions I'd like you to give an answer on a scale of nought to 10, where nought is 'not at all' and 10 is 'completely'"

The questions were: "Overall, how anxious did you feel yesterday?", "Overall, how happy did you feel yesterday?", "Overall, to what extent do you feel that the things you do in your life are worthwhile?", and "Overall, how satisfied are you with your life nowadays?". These responses were reduced to a single variable using factor analysis, as described below.

Self-reported health was measured using the question "How is your health in general; is it...", with the response options: "Very good", "Good", "Fair", "Bad", and "Very bad". These responses were dichotomised so that "Fair", "Bad", and "Very bad" were given a value of 1 and "Very good" and "Good" were given a value of 0 . This maximised similarity with the majority[8-10,12] of the key previous studies.

\section{Area-level data}

The unit of geography used was the middle super output area (MSOA). MSOAs are units of UK census geography with a population of $\sim 8000$. There are 410 MSOAs in Wales. Individual-level data were linked to two sets of area-level data at the MSOA level using linking codes supplied by the Welsh Government.

Firstly, they were linked to previously reported MRP estimates of sense of belonging in each MSOA[13], estimated using the 2016/17 wave of the NSfW (not included here, to maintain independence of area and individual-level data). The full process for computing these estimates is given elsewhere[13], but briefly: a mixed effects model predicting whether respondents indicated a sense of belonging to their area using their dichotomised response to the belonging question described above (strongly agree, tend to agree, and neither agree nor disagree, vs tend to disagree, and strongly disagree). The predictors to the model included area-level variables (the degree of residential turnover[26], and the level of unemployment according to the Welsh index of multiple deprivation[27] and demographic variables (age, sex, national identity, and ability to speak Welsh[21], as well as random effects for each MSOA and local authority (county). For each MSOA, the resulting demographic coefficients were weighted by the 
proportion of the population each segment represented in the given MSOA, according to the 2011 Census, and summed with the relevant area-level coefficients, area-level random effects, and intercept to derive an estimated percentage of the population of each MSOA who felt they belonged to their local area. See Figure 1 for a map.

Individual-level data were also linked to MSOA-level measures of the percentage of residents receiving low income support, as a proxy for poverty, from the Welsh Index of Multiple Deprivation.

Respondents' data were excluded if they were missing data for age, education, general health, any of the wellbeing measures, or individual-level belonging (including Don't know responses).

\section{Analyses}

Factor analysis was used to collapse the four wellbeing items into a single measure, using the factanal function in R[25] to produce Bartlett scores.

Four linear mixed effects models were fitted separately to mental wellbeing and selfreported health data as follows. Model 1 included individual-level belonging, area-level belonging (z-scored, mean=89.26, SD=3.27), and their interaction as fixed effects. A random intercept for each MSOA in each wave of the NSfW survey (so 410 MSOAs x 3 survey waves), nested within local authority was also included to account for the dependent structure of the data Residuals were weighted by sampling weights. Model 2 was as Model 1, but added gender and age. Model 3 was as Model 2, but added education. Model 4 was as Model 3, but added area-level income deprivation (z-scored, mean=15.57, SD=7.04). Models were fitted using the glmmTMB function in the $\mathrm{R}$ package of the same name[28]. Multicollinearity was checked using the check_collinearity function in the performance package[29]. In all models, the reference categories were male for gender, degree-level qualifications for education, and Strongly agree for belonging.

To assess whether the same results are found using MRP and by using the traditional approach of simply aggregating data by geographical unit, the analyses were repeated using belonging estimates derived by taking a proportion of respondents indicating that they Strongly agree, Tend to agree, or Neither agree nor disagree that they belong to their area (weighted by sampling weight).

To evaluate the out-of-sample performance of the modelling, Model 4 for both outcomes was refitted to 20 random subsets of $90 \%$ of the data and, for each iteration, predictions for the remaining $10 \%$ were compared to actual outcomes. For general health, area under the curve (AUC), computed using the pROC package[30] for R was used to measure performance and for wellbeing Pearson's correlations were used.

\section{Results}

After excluding data for those missing age $(n=47)$, gender $(n=4)$, education $(n=30)$, general health $(n=45)$, any of the wellbeing measures $(n=595)$, or individual-level 
belonging (only a subsample of the 2012/13 and 2014/15 waves were asked about belonging, but of those who were asked: $n=130 . n=15,974$ who were not asked this question were excluded), data were available for 27,828 respondents.

Table 1 shows numbers of respondents for each level of gender, age, education, and area-level belonging (expressed in quartiles), both in total and broken down by individual-level sense of belonging. Majorities felt they belonged across every category of the sample, but age, education, self-rated health, and area-level belonging showed positive relationships with individual-level belonging.

\section{Insert Table 1 here}

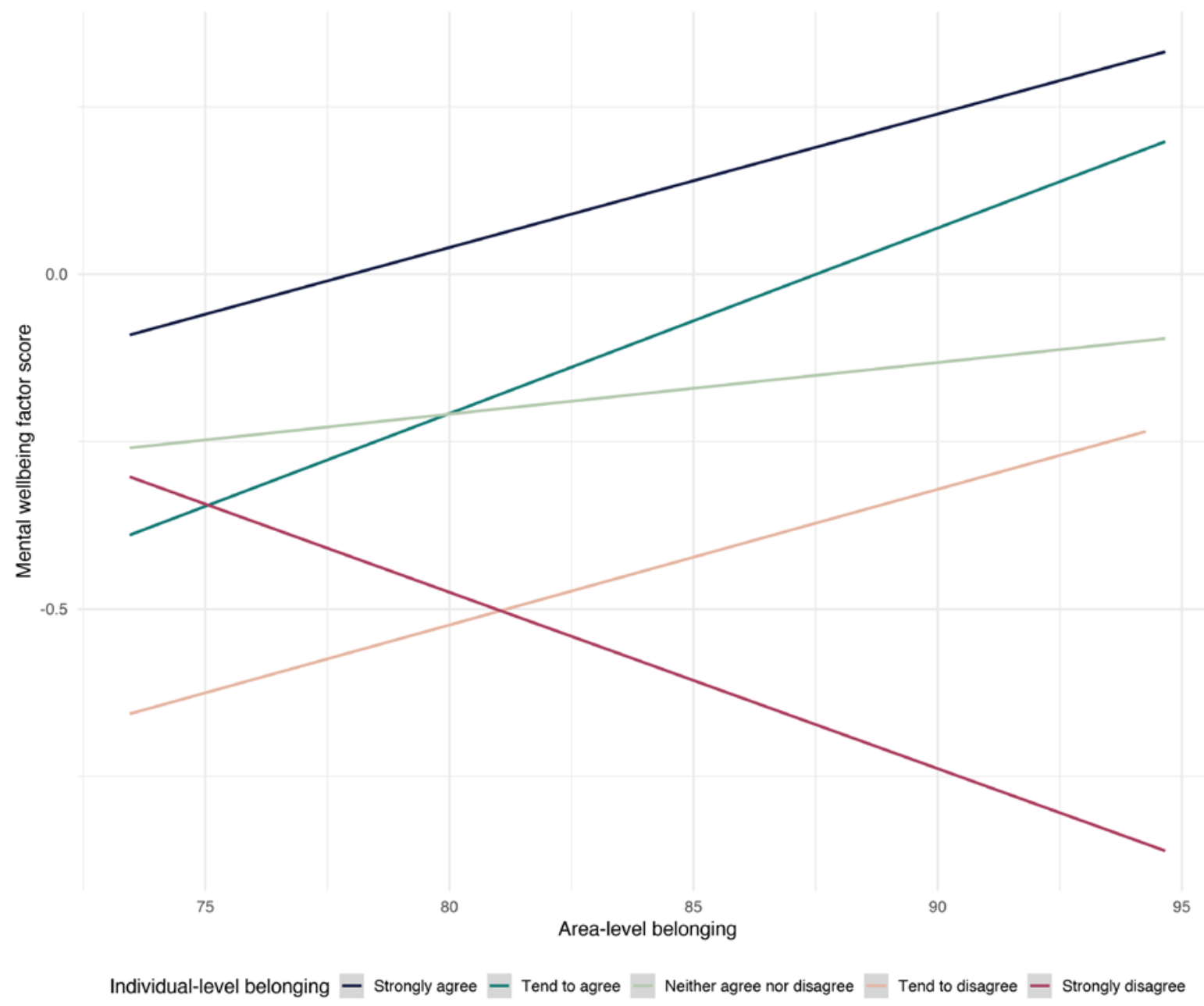

Figure 2. Regression lines of mental wellbeing on ecological sense of belonging for the five levels of individual sense of belonging separately. Datapoints not presented to avoid disclosure of identities.

Figure 2 shows separate regression lines for wellbeing on area-level capital for respondents reporting each of the five levels of individual-level belonging. More positive individual-level views on belonging are associated with greater wellbeing. Living in an area with greater sense of belonging is associated with higher wellbeing, 
except for respondents who strongly disagree that they belong, where it is associated with lower wellbeing.

This impression is supported by the mixed effects models (see Table 2). In all cases, there is a significant interaction between area-level belonging and strong disagreement that one belongs to their local area. This interaction survives adjustment for age, sex, education, and area-level poverty.

Variance inflation factors suggested that multicollinearity was generally low - the highest value being 3.6 for area-level belonging in Model 4.

There was evidence of a slight ceiling effect on wellbeing scores, with scores reaching ceiling at the $94^{\text {th }}$ percentile. However, given this ceiling effect was more pronounced in respondents that felt they belonged to their local area, if anything this ceiling would have led to an underestimate of the interaction identified for those who felt they did not belong.

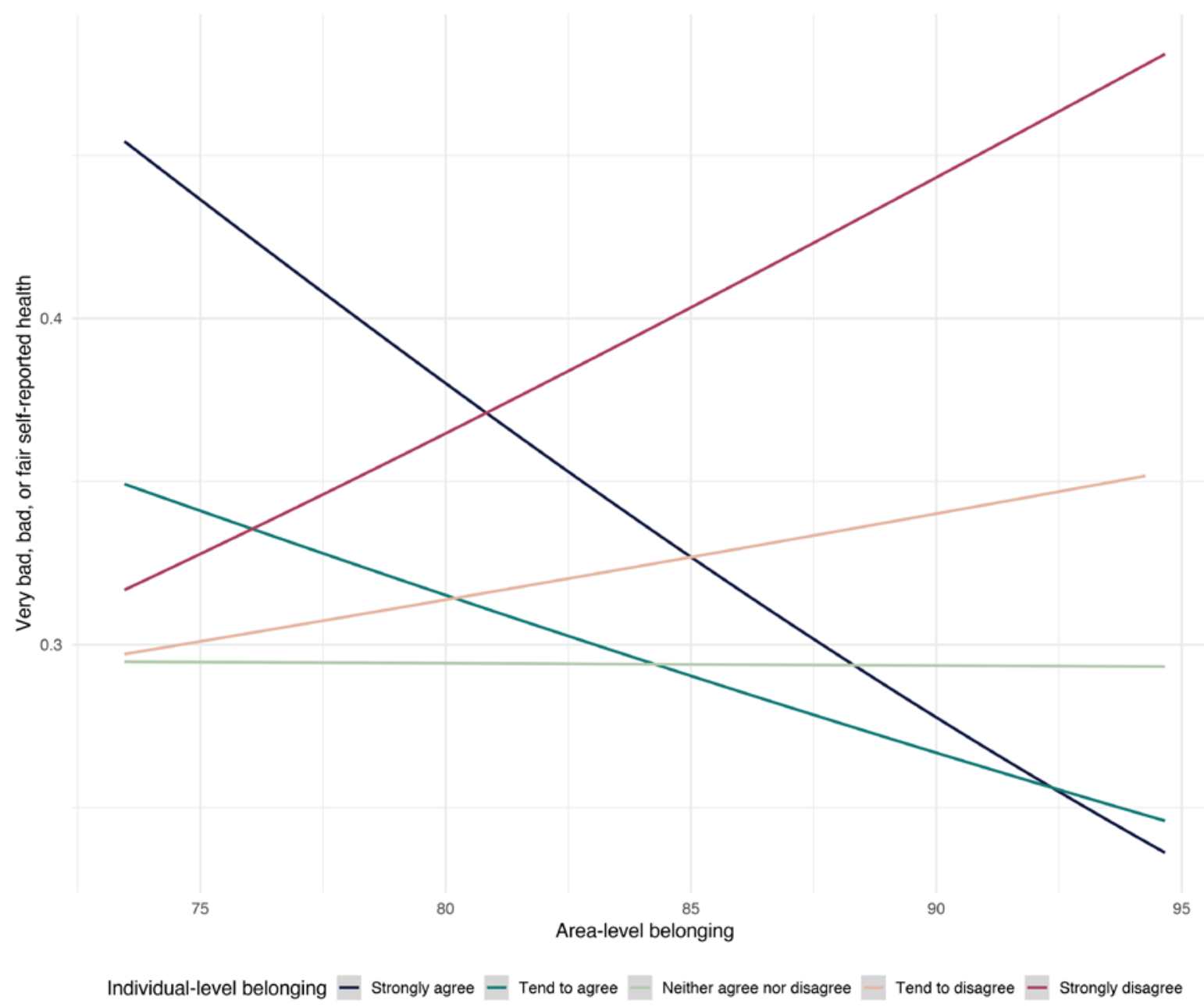

Figure 3. Regression lines of self-reported health on ecological sense of belonging for the five levels of individual sense of belonging separately. Datapoints not presented to avoid disclosure of identities. 
Figure 3 shows separate regression lines for self-reported health on area-level capital for respondents reporting each of the five levels of individual-level belonging. The association between area-level belonging and probability of reporting poorer health becomes increasingly positive as individual-level belonging decreases, changing direction around the middle of the scale.

This pattern is confirmed in the regression models, the results of which are available in Table 3. In all models there is an interaction between the lower levels of individual-level belonging and area-level belonging. The statistical significance of the interaction for tend to agree and neither agree nor disagree varies on the model in question, becoming non-significant in the more adjusted models, but the same pattern is evident across all models.

Full results for the analysis using area estimates of belonging derived using simple aggregation of data by MSOA can be found in the Supplementary Materials but, briefly, the cross-level interaction was not found for mental wellbeing in this analysis while the analysis for general health was replicated, albeit in an attenuated fashion.

Out of sample performance was fairly modest for both general health (AUC=.698-.699) and mental wellbeing ( $r=.300-.304)$, but adequate, given that the models were designed to test a hypothesis, rather than for clinical or policy decision-making.

\section{Discussion}

These analyses replicate previously reported cross-level interactions between individual and area-level measures of social capital on mental wellbeing and selfreported health, on a level of geography orders of magnitude finer than previous studies. This finding is further evidence for the so-called 'dark side of social capital'[7]: ecological social capital's positive association with health only applies for in-group members, and the relationship for members of the out-group is negative.

A number of different, but non-mutually exclusive, explanations can be advanced. A useful framework here is that of Szreter and Woolcock[31], who contrast social capital mechanisms that operate through perceptions and those that operate through material conditions. The perception-based mechanisms work on the basis that feeling like a member of a minority or a social out-group can be unpleasant[32]. Such an explanation is similar to that of Marmot and colleagues, who have convincingly linked subjective social status to health outcomes[33,34]. Areas with high belonging may be those where the area is saliently associated with a particular social group, and where those who do not belong to that group would be keenly aware of the fact.

Alternatively, the health benefits of social capital can be explained by greater access to material resources. Bourdieu's[35] conceptualisation of the different forms of capital emphasises that social, cultural, and economic capital reinforce one another. Thus social capital may not have a direct effect on health, but can be used to improve an individual or a community's material circumstances. Furthermore, social and cultural capital are thought to have health-promoting roles beyond their association with economic capital and provision of access to material resources, shaping norms and behaviour, through the maintenance of health-relevant practices and norms[2,36,37]. Those excluded from 
groups with health-promoting behavioural norms may signal their social status by rejecting these practices and norms.

Another important question is whether people's outsider status depends on explicit social identities and communities, or a more implicit sense of belonging. Research into the group density effect, the positive correlation between people's mental health and the proportion of the local population their social group represents[38-40], shows that socially salient group identities, such as ethnicity, can lead to group density dynamics, but it is unclear on whether they rely on explicit identities. Research on newly formed Brexit identities in the United Kingdom, where group density effects for 'remainer' and 'leaver' identities only manifested after the referendum on European Union membership, suggests that such explicit identities, rather than broader underlying cultural mismatch, may be a necessary component of such effects.

There are a number of limitations to acknowledge. Firstly, the analyses are crosssectional and a causal effect of social capital on health cannot be assumed. Indeed a bidirectional relationship between sense of belonging and health seems plausible. Secondly, social capital is a multi-faceted construct and here only one facet, sense of belonging, is examined. These results are similar to previous results using other constructs and sense of belonging appears to be related to network measures of social capital[20], so this issue could be overstated, but is important to consider. Thirdly, the measure of mental wellbeing had a ceiling effect and is not widely used. In mitigation, these questions are present in the majority of waves of the NSfW, and using other measures of mental wellbeing would have involved a major reduction in sample size. As mentioned above, the ceiling effect, if anything, biased the interaction of interest in the direction of the null hypothesis. Furthermore, this was not the only outcome measure used, and results were consistent with those for self-reported health.

The present study also had a number of strengths. Firstly, area-level social capital is estimated on a much finer spatial scale than in previous studies. Three of the five previous studies estimate social capital on the country level[9-11], while two[8,12], using the same dataset, looked at 40 American counties, groups of counties, and states. These geographies were finer-grained than countries, but still represented substantial populations, containing in some cases millions of inhabitants. Conversely, the present study used MSOAs, with an average population of 8000. Given this difference in spatial scale, it is reassuring to see similar results to previous studies. Secondly, the present study looks at a greater number of geographical units than previous studies. Previous studies have looked at between 22 and 50 geographical units. Here, 410 MSOAs were used, giving much more granular variation in social capital. Thirdly, in order to measure social capital on such a fine scale, MRP was used, instead of relying on entire surveys in separate countries or communities. Supplementary analyses suggest that the MRP estimates are better able to detect cross-level interactions, providing further evidence of the advantages of MRP over the simple aggregation used in some multi-level analyses of social capital. Finally, like previous studies in this area, the study used a large highquality survey dataset with many thousands of respondents, which is likely why findings have replicated well across settings and different facets of social capital.

There are two clear implications to this work. Firstly, it highlights the risks of looking at geographical health inequalities only in the aggregate - here some of the worst outcomes were suffered by those living in areas with the highest aggregate social 
capital. In Wales, and likely elsewhere, this is particularly pertinent in rural health, where aggregate risk indices can hide a minority of very poor outcomes. Secondly, it supports previous work showing that social capital is not always a benign, unambiguously health-promoting social good. Policy-makers should not see it as a virtuous counterpart to economic capital. Like economic capital, while it is often a solution to health problems, it can also be a cause of them.

To conclude, the present study confirms previously demonstrated cross-level social capital interactions at a finer spatial scale than existing research. It is increasingly clear that social capital can be a double-edged sword when it comes to public health associated with better health status for those who are well-integrated into communities but potentially harmful for social outsiders.

1 Kawachi I. Social Capital and Community Effects on Population and Individual Health. Annals of the New York Academy of Sciences 1999;896:120-30. doi:10.1111/j.1749-6632.1999.tb08110.x

2 Lochner KA, Kawachi I, Brennan RT, et al. Social capital and neighborhood mortality rates in Chicago. Social Science \& Medicine 2003;56:1797-805. doi:10.1016/S02779536(02)00177-6

3 Ehsan AM, De Silva MJ. Social capital and common mental disorder: a systematic review. J Epidemiol Community Health 2015;69:1021-8. doi:10.1136/jech-2015205868

4 Subramanian SV, Lochner KA, Kawachi I. Neighborhood differences in social capital: a compositional artifact or a contextual construct? Health \& Place 2003;9:33-44. doi:10.1016/S1353-8292(02)00028-X

5 Snelgrove JW, Pikhart H, Stafford M. A multilevel analysis of social capital and selfrated health: Evidence from the British Household Panel Survey. Social Science \& Medicine 2009;68:1993-2001. doi:10.1016/j.socscimed.2009.03.011

6 Hamano T, Fujisawa Y, Ishida Y, et al. Social Capital and Mental Health in Japan: A Multilevel Analysis. PLOS ONE 2010;5:e13214. doi:10.1371/journal.pone.0013214

7 Villalonga-Olives E, Kawachi I. The dark side of social capital: A systematic review of the negative health effects of social capital. Social Science \& Medicine 2017;194:10527. doi:10.1016/j.socscimed.2017.10.020

8 Subramanian SV, Kim DJ, Kawachi I. Social Trust and Self-Rated Health in US Communities: a Multilevel Analysis. Journal of Urban Health: Bulletin of the New York Academy of Medicine 2002;79:21S - 34. doi:10.1093/jurban/79.suppl_1.S21

9 Elgar FJ, Davis CG, Wohl MJ, et al. Social capital, health and life satisfaction in 50 countries. Health \& Place 2011;17:1044-53. doi:10.1016/j.healthplace.2011.06.010

10 Poortinga W. Social capital: An individual or collective resource for health? Social Science \& Medicine 2006;62:292-302. doi:10.1016/j.socscimed.2005.06.008 
11 Campos-Matos I, Subramanian SV, Kawachi I. The 'dark side' of social capital: trust and self-rated health in European countries. Eur J Public Health 2016;26:90-5. doi:10.1093/eurpub/ckv089

12 Kim D, Subramanian SV, Kawachi I. Bonding versus bridging social capital and their associations with self rated health: a multilevel analysis of 40 US communities. Journal of Epidemiology \& Community Health 2006;60:116-22. doi:10.1136/jech.2005.038281

13 Saville CWN. Estimating ecological social capital using multi-level regression with post-stratification: A spatial analysis of psychiatric admission rates in wales. Health \& Place 2019;59:102187. doi:10.1016/j.healthplace.2019.102187

14 Twigg L, Barnard S, Mohan J, et al. Developing and Evaluating Small-Area Indicators of the Neighbourhood Social Environment. Environ Plan A 2006;38:2173-92. doi:10.1068/a36213

15 Page N, Higgs G, Langford M. An exploratory analysis of spatial variations in organ donation registration rates in Wales prior to the implementation of the Human Transplantation (Wales) Act 2013. Health \& Place 2018;52:18-24. doi:10.1016/j.healthplace.2018.05.002

16 Saville CWN. Ecological social capital does not predict geographical variance in increases in depression following the 2008 financial crisis. $\mathrm{Br} J$ Psychol 2020;:bjop.12448. doi:10.1111/bjop.12448

17 Gelman A, Little TC, Witter MSD. Poststratification Into Many Categories Using Hierarchical Logistic Regression. 1997;:17.

18 Twigg L, Moon G, Jones K. Predicting small-area health-related behaviour: a comparison of smoking and drinking indicators. Social Science \& Medicine 2000;50:1109-20. doi:10.1016/S0277-9536(99)00359-7

19 Mohan J, Twigg L, Barnard S, et al. Social capital, geography and health: a small-area analysis for England. Social Science \& Medicine 2005;60:1267-83.

doi:10.1016/j.socscimed.2004.06.050

20 Carpiano RM, Hystad PW. "Sense of community belonging" in health surveys: What social capital is it measuring? Health \& Place 2011;17:606-17. doi:10.1016/j.healthplace.2010.12.018

21 Office for National Statistics, National Records of Scotland, Northern Ireland Statistics and Research Agency. 2011 Census aggregate data. UK Data Service (Edition: June 2016). 2016. http://dx.doi.org/10.5257/census/aggregate-2011-1

22 Welsh Government. National Survey for Wales, 2012-2013. [data collection]. 2020.http://doi.org/10.5255/UKDA-SN-7320-1

23 Welsh Government. National Survey for Wales, 2014-2015. [data collection]. 2020.http://doi.org/10.5255/UKDA-SN-7767-2 
24 Welsh Government. National Survey for Wales, 2018-2019. [data collection]. 2020.http://doi.org/10.5255/UKDA-SN-8591-1

25 R Core Team. R: A language and environment for statistical computing. Vienna, Austria: : R Foundation for Statistical Computing 2019. http://www.R-project.org/

26 Lansley G, Li W, Longley PA. Creating a linked consumer register for granular demographic analysis. J R Stat Soc A 2019;182:1587-605. doi:10.1111/rssa.12476

27 Welsh Government. Welsh Index of Multiple Deprivation (WIMD). 2014.

28 Brooks ME, Kristensen K, van Benthem KJ, et al. glmmTMB Balances Speed and Flexibility Among Packages for Zero-inflated Generalized Linear Mixed Modeling. The R Journal 2017;9:378-400.

29 Lüdecke D, Makowski D, Waggoner P. performance: Assessment of Regression Models Performance. $R$ package. 2019. https://CRAN.R-project.org/package=performance

30 Xavier R, Turck N, Hainard A, et al. pROC: an open-source package for R and S+ to analyze and compare ROC curves. BMC Bioinformatics 2011;:77. doi:DOI: 10.1186/1471-2105-12-77

31 Szreter S, Woolcock M. Health by association? Social capital, social theory, and the political economy of public health. Int J Epidemiol 2004;33:650-67. doi:10.1093/ije/dyh013

32 Meyer IH. Minority Stress and Mental Health in Gay Men. Journal of Health and Social Behavior 1995;36:38. doi:10.2307/2137286

33 Singh-Manoux A, Adler NE, Marmot MG. Subjective social status: its determinants and its association with measures of ill-health in the Whitehall II study. Social Science \& Medicine 2003;56:1321-33. doi:10.1016/S0277-9536(02)00131-4

34 Marmot M. Status syndrome. Significance 2004;1:150-4. doi:10.1111/j.17409713.2004.00058.x

35 Bourdieu P. The Forms of Capital. In: Biggart NW, ed. Readings in Economic Sociology. Oxford, UK: : Blackwell Publishers Ltd 2002. 280-91. doi:10.1002/9780470755679.ch15

36 Abel T. Cultural capital and social inequality in health. Journal of Epidemiology \& Community Health 2008;62:e13-e13. doi:10.1136/jech.2007.066159

37 Clercq BD, Abel T, Moor I, et al. Social inequality in adolescents' healthy food intake: the interplay between economic, social and cultural capital. ;:8.

38 Shaw RJ, Atkin K, Bécares L, et al. Impact of ethnic density on adult mental disorders: narrative review. Br J Psychiatry 2012;201:11-9.

doi:10.1192/bjp.bp.110.083675 
39 Bécares L, Cormack D, Harris R. Ethnic density and area deprivation: Neighbourhood effects on Māori health and racial discrimination in Aotearoa/New Zealand. Social Science \& Medicine 2013;88:76-82. doi:10.1016/j.socscimed.2013.04.007

40 Baker SJ, Jackson M, Jongsma $\mathrm{H}$, et al. A comprehensive systematic review and multilevel meta-analysis of the ethnic density effect in psychosis. 2020.https://psyarxiv.com/jcxzw/ 


\begin{tabular}{|c|c|c|c|c|c|c|c|}
\hline & & & & Individual-level belongi & & & \\
\hline & & Strongly agree & Tend to agree & Neither agree nor disagree & Tend to disagree & Strongly disagree & Total \\
\hline \multirow{2}{*}{ Gender } & Male & 5,244 & 4,355 & 1,754 & 763 & 276 & 12,392 \\
\hline & Female & 6,493 & 5,331 & 2,275 & 959 & 378 & 15,436 \\
\hline \multirow{10}{*}{ Age } & Aged $16-24.3$ & 568 & 662 & 333 & 161 & 74 & 1,798 \\
\hline & Aged 24.3-32.6 & 790 & 912 & 587 & 219 & 112 & 2,620 \\
\hline & Aged 32.6-40.9 & 1,012 & 1,091 & 573 & 206 & 93 & 2,975 \\
\hline & Aged 40.9-49.2 & 1,417 & 1,448 & 671 & 263 & 90 & 3,889 \\
\hline & Aged 49.2-57.5 & 1,517 & 1,349 & 552 & 217 & 79 & 3,714 \\
\hline & Aged 57.5-65.8 & 1,889 & 1,394 & 493 & 237 & 90 & 4,103 \\
\hline & Aged 65.8-74.1 & 2,209 & 1,538 & 507 & 240 & 64 & 4,558 \\
\hline & Aged 74.1-82.4 & 1,456 & 855 & 216 & 119 & 31 & 2,677 \\
\hline & Aged 82.4-90.7 & 765 & 391 & 81 & 54 & 16 & 1,307 \\
\hline & Aged 90.7-99.1 & 114 & 46 & 16 & 6 & 5 & 187 \\
\hline \multirow{3}{*}{ Education } & Degree-level & 1,986 & 2,000 & 1,020 & 386 & 124 & 5,516 \\
\hline & Non-degree level & 6,649 & 5,835 & 2,505 & 1,024 & 389 & 16,402 \\
\hline & No qualifications & 3,102 & 1,851 & 504 & 312 & 141 & 5,910 \\
\hline \multirow{4}{*}{$\begin{array}{c}\text { Ecological social } \\
\text { capital }\end{array}$} & Top quartile & 3,153 & 2,480 & 866 & 352 & 105 & 6,956 \\
\hline & Third quartile & 2,950 & 2,499 & 948 & 376 & 143 & 6,916 \\
\hline & Second quartile & 2,849 & 2,429 & 1,097 & 437 & 165 & 6,977 \\
\hline & Bottom quartile & 2,785 & 2,278 & 1,118 & 557 & 241 & 6,979 \\
\hline \multirow{2}{*}{ Self-rated health } & $\begin{array}{l}\text { Very good or good. } \\
\text { Fair, bad, or very }\end{array}$ & 7926 & 6613 & 2704 & 1055 & 347 & 18,645 \\
\hline & & 3811 & 3073 & 1325 & 667 & 307 & 9,183 \\
\hline \multicolumn{2}{|c|}{ TOTAL } & 11,737 & 9,686 & 4,029 & 1,722 & 654 & 27,828 \\
\hline
\end{tabular}

Table 1. Cross-tabulation of respondents by individual-level sense of belonging and other respondent characteristics. 


\begin{tabular}{|c|c|c|c|c|c|c|c|c|c|c|c|c|}
\hline \multirow[b]{2}{*}{ Term } & \multicolumn{3}{|c|}{$\begin{array}{c}\text { Model } 1 \\
I C C=.028 \\
R^{2}=.070 \\
\text { AIC }=80522.86\end{array}$} & \multicolumn{3}{|c|}{$\begin{array}{c}\text { Model } 2 \\
I C C=.028 \\
R^{2}=.082 \\
\text { AIC }=80253.21\end{array}$} & \multicolumn{3}{|c|}{$\begin{array}{c}\text { Model } 3 \\
I C C=.027 \\
R^{2}=.088 \\
\text { AIC }=80093.01\end{array}$} & \multicolumn{3}{|c|}{$\begin{array}{c}\text { Model } 4 \\
I C C=.027 \\
R^{2}=.088 \\
\text { AIC }=80091.49\end{array}$} \\
\hline & Coef & $2.5 \% \mathrm{Cl}$ & $97.5 \% \mathrm{Cl}$ & Coef & $2.5 \% \mathrm{Cl}$ & $97.5 \% \mathrm{Cl}$ & Coef & $2.5 \% \mathrm{Cl}$ & $97.5 \% \mathrm{Cl}$ & Coef & $2.5 \% \mathrm{Cl}$ & $97.5 \% \mathrm{Cl}$ \\
\hline Tend to agree * Area-level belonging & .019 & -.009 & .047 & .023 & -.004 & .051 & .026 & -.002 & .054 & .026 & -.002 & .054 \\
\hline $\begin{array}{c}\text { Neither agree nor disagree } * \text { Area-level } \\
\text { belonging }\end{array}$ & -.034 & -.069 & .000 & -.030 & -.064 & .005 & -.021 & -.055 & .014 & -.021 & -.055 & .014 \\
\hline Tend to disagree * Area-level belonging & .004 & -.043 & .051 & .003 & -.043 & .050 & .009 & -.038 & .055 & .009 & -.038 & .055 \\
\hline Strongly disagree * Area-level belonging & -.155 & -.222 & -.087 & -.154 & -.221 & -.087 & -.143 & -.210 & -.076 & -.143 & -.210 & -.076 \\
\hline Tend to agree & -.180 & -.208 & -.152 & -.178 & -.206 & -.150 & -.185 & -.213 & -.157 & -.185 & -.213 & -.157 \\
\hline Neither agree nor disagree & -.360 & -.396 & -.323 & -.358 & -.394 & -.321 & -.374 & -.410 & -.337 & -.374 & -.411 & -.338 \\
\hline Tend to disagree & -.557 & -.609 & -.505 & -.562 & -.614 & -.510 & -.573 & -.626 & -.521 & -.573 & -.626 & -.521 \\
\hline Strongly disagree & -.937 & -1.021 & -.853 & -.941 & -1.025 & -.858 & -.936 & -1.020 & -.853 & -.936 & -1.019 & -.852 \\
\hline Area-level belonging (z-scored) & .072 & .048 & .096 & .074 & .050 & .098 & .057 & .034 & .080 & .036 & .005 & .068 \\
\hline Female & & & & .020 & -.004 & .044 & .026 & .002 & .050 & .026 & .002 & .050 \\
\hline Aged 24.3-32.6 & & & & -.045 & -.093 & .002 & -.068 & -.116 & -.020 & -.066 & -.114 & -.018 \\
\hline Aged 32.6-40.9 & & & & -.100 & -.149 & -.052 & -.123 & -.172 & -.074 & -.121 & -.169 & -.072 \\
\hline Aged 40.9-49.2 & & & & -.223 & -.268 & -.178 & -.234 & -.279 & -.189 & -.232 & -.277 & -.186 \\
\hline Aged 49.2-57.5 & & & & -.265 & -.311 & -.219 & -.260 & -.307 & -.214 & -.258 & -.305 & -.212 \\
\hline Aged 57.5-65.8 & & & & -.112 & -.159 & -.065 & -.094 & -.142 & -.047 & -.092 & -.140 & -.045 \\
\hline Aged 65.8-74.1 & & & & .056 & .008 & .104 & .094 & .045 & .143 & .096 & .047 & .145 \\
\hline Aged 74.1-82.4 & & & & -.045 & -.102 & .011 & .016 & -.041 & .074 & .017 & -.040 & .075 \\
\hline Aged 82.4-90.7 & & & & -.161 & -.235 & -.088 & -.086 & -.161 & -.011 & -.085 & -.160 & -.010 \\
\hline Aged 90.7-99.1 & & & & -.192 & -.367 & -.017 & -.098 & -.274 & .077 & -.098 & -.273 & .078 \\
\hline Non-degree qualifications & & & & & & & -.114 & -.146 & -.083 & -.111 & -.143 & -.080 \\
\hline No qualifications & & & & & & & -.277 & -.320 & -.235 & -.273 & -.315 & -.230 \\
\hline Area-level income deprivation (z-scored) & & & & & & & & & & -.025 & -.050 & .001 \\
\hline
\end{tabular}


Table 2. Odds ratios (OR) and 95\% confidence intervals for each term in the four models examining mental wellbeing. ICC=conditional intra-class correlation, $\mathrm{R}^{2}=$ Nakagawa $\mathrm{R}^{2}$ (ICC and $\mathrm{R}^{2}$ calculated with performance package for $\mathrm{R}$ ), AIC=Aikake information criteria. Code for models:

glmmTMB(Wellbeing IndividualBelong * scale(AreaBelonging) + (1| LocalAuthority /MSOAYear), weights = SampleAdultWeight, data = NSfW) $>>$ Model1

glmmTMB(Wellbeing IndividualBelong * scale(AreaBelonging) + AgeGroup + Gender + (1| LocalAuthority /MSOAYear), weights = SampleAdultWeight, data = NSfW) $->$ Model2

glmmTMB(Wellbeing IndividualBelong * scale(AreaBelonging) + AgeGroup + Gender + Education $+(1 \mid$ LocalAuthority $/$ MSOAYear $)$, weights $=$ SampleAdultWeight, data = NSfW) -> Model3

glmmTMB(Wellbeing IndividualBelong * scale(AreaBelonging) + AgeGroup + Gender + Education + scale(ArealncomeDeprivation) + (1| LocalAuthority /MSOAYear), weights $=$ SampleAdultWeight, data $=$ NSfW) $->$ Model4 


\begin{tabular}{|c|c|c|c|c|c|c|c|c|c|c|c|c|}
\hline Term & \multicolumn{3}{|c|}{$\begin{array}{c}\text { Model } 1 \\
I C C=.047 \\
R^{2}=.056 \\
\text { AIC }=33118.21 \\
\end{array}$} & \multicolumn{3}{|c|}{$\begin{array}{c}\text { Model } 2 \\
I C C=.041 \\
R^{2}=.156 \\
\text { AIC }=30977.36 \\
\end{array}$} & \multicolumn{3}{|c|}{$\begin{array}{c}\text { Model } 3 \\
I C C=.034 \\
R^{2}=.174 \\
\text { AIC }=30494.89\end{array}$} & \multicolumn{3}{|c|}{$\begin{array}{c}\text { Model } 4 \\
I C C=.030 \\
R^{2}=.175 \\
\text { AIC }=30459.5\end{array}$} \\
\hline Tend to agree * Area-level belonging & 1.06 & 1.00 & 1.13 & 1.04 & 0.98 & 1.11 & 1.04 & 0.97 & 1.11 & 1.04 & 0.98 & 1.11 \\
\hline $\begin{array}{c}\text { Neither agree nor disagree * Area-level } \\
\text { belonging }\end{array}$ & 1.13 & 1.05 & 1.22 & 1.12 & 1.03 & 1.21 & 1.08 & 1.00 & 1.17 & 1.08 & 1.00 & 1.17 \\
\hline Strongly disagree * Area-level belonging & 1.26 & 1.10 & 1.46 & 1.24 & 1.07 & 1.43 & 1.20 & 1.03 & 1.38 & 1.18 & 1.01 & 1.36 \\
\hline Tend to agree & 0.93 & 0.87 & 0.99 & 1.10 & 1.03 & 1.17 & 1.14 & 1.06 & 1.21 & 1.14 & 1.06 & 1.21 \\
\hline Neither agree nor disagree & 1.04 & 0.96 & 1.13 & 1.47 & 1.35 & 1.60 & 1.58 & 1.45 & 1.72 & 1.58 & 1.45 & 1.73 \\
\hline Tend to disagree & 1.30 & 1.16 & 1.45 & 1.73 & 1.54 & 1.94 & 1.83 & 1.63 & 2.06 & 1.83 & 1.63 & 2.06 \\
\hline Strongly disagree & 1.93 & 1.63 & 2.29 & 2.84 & 2.37 & 3.40 & 2.84 & 2.37 & 3.41 & 2.83 & 2.36 & 3.39 \\
\hline Area-level belonging (z-scored) & 0.83 & 0.79 & 0.88 & 0.77 & 0.73 & 0.81 & 0.82 & 0.78 & 0.87 & 0.96 & 0.90 & 1.02 \\
\hline Female & & & & 1.10 & 1.04 & 1.16 & 1.07 & 1.01 & 1.13 & 1.07 & 1.01 & 1.13 \\
\hline Aged 24.3-32.6 & & & & 1.43 & 1.25 & 1.63 & 1.56 & 1.37 & 1.78 & 1.54 & 1.35 & 1.76 \\
\hline Aged 32.6-40.9 & & & & 1.66 & 1.46 & 1.89 & 1.81 & 1.59 & 2.07 & 1.78 & 1.56 & 2.03 \\
\hline Aged 40.9-49.2 & & & & 2.27 & 2.01 & 2.56 & 2.37 & 2.10 & 2.67 & 2.32 & 2.06 & 2.62 \\
\hline Aged 49.2-57.5 & & & & 3.54 & 3.14 & 3.99 & 3.49 & 3.09 & 3.93 & 3.42 & 3.03 & 3.86 \\
\hline Aged 57.5-65.8 & & & & 4.39 & 3.89 & 4.96 & 4.14 & 3.66 & 4.67 & 4.06 & 3.60 & 4.59 \\
\hline Aged 65.8-74.1 & & & & 5.26 & 4.65 & 5.94 & 4.59 & 4.06 & 5.20 & 4.52 & 4.00 & 5.12 \\
\hline Aged 74.1-82.4 & & & & 8.29 & 7.24 & 9.49 & 6.72 & 5.85 & 7.71 & 6.64 & 5.79 & 7.62 \\
\hline Aged 82.4-90.7 & & & & 10.53 & 8.90 & 12.46 & 8.17 & 6.88 & 9.70 & 8.08 & 6.80 & 9.59 \\
\hline Aged 90.7-99.1 & & & & 9.28 & 6.43 & 13.39 & 6.74 & 4.64 & 9.79 & 6.68 & 4.61 & 9.70 \\
\hline Non-degree qualifications & & & & & & & 1.70 & 1.57 & 1.84 & 1.67 & 1.54 & 1.81 \\
\hline No qualifications & & & & & & & 2.99 & 2.71 & 3.30 & 2.90 & 2.62 & 3.20 \\
\hline Area-level income deprivation (z-scored) & & & & & & & & & & 1.20 & 1.13 & 1.26 \\
\hline
\end{tabular}


Table 3. Odds ratios (OR) and 95\% confidence intervals for each term in the four models examining self-rated health. ICC $=$ conditional intra-class correlation, $\mathrm{R}^{2}=$ Nakagawa $\mathrm{R}^{2}$ (ICC and $\mathrm{R}^{2}$ calculated with performance package for $\mathrm{R}$ ), AIC=Aikake information criteria. Code for models:

glmmTMB(Health_VBad_Bad_Fair IndividualBelong * scale(AreaBelonging $)+(1 \mid$ LocalAuthority /MSOAYear $)$, weights = SampleAdultWeight, family = 'binomial', data = NSfW) $\rightarrow$ Model1

glmmTMB(Health_VBad_Bad_Fair IndividualBelong * scale(AreaBelonging $)+$ AgeGroup + Gender + (1| LocalAuthority /MSOAYear), weights = SampleAdultWeight, family $=$ 'binomial', data $=$ NSfW) $->$ Model2

glmmTMB(Health_VBad_Bad_Fair IndividualBelong * scale(AreaBelonging) + AgeGroup + Gender + Education + (1| LocalAuthority /MSOAYear), weights =

SampleAdultWeight, family = 'binomial', data = NSfW) $\rightarrow$ Model3

glmmTMB(Health_VBad_Bad_Fair IndividualBelong * scale(AreaBelonging) + AgeGroup + Gender + Education + scale(ArealncomeDeprivation) + (1| LocalAuthority

/MSOAYear), weights = SampleAdultWeight, family = 'binomial', data = NSfW) $->$ Model4 